Review Article

\title{
Predatory journals as threats to the academic publishing: a review
}

\author{
Jiban Shrestha
}

Nepal Agricultural Research Council, National Plant Breeding and Genetics Research Centre, Khumaltar, Lalitpur, Nepal.

Correspondence: jibshrestha@gmail.com

ORCID: https://orcid.org/0000-0002-3755-8812

Received: June 11, 2020; Revised: October 25, 2020;

Accepted: December 15, 2020; Available online: January 01, 2021

(c) Copyright: Shrestha, J. (2021).

\author{
(c) (1) T) This work is licensed under a Creative Commons Attribution-Non Commercial 4.0 \\ International License.
}

\begin{abstract}
Academic publishing has been increasing greatly with the spread of open access journals and the shift to online publishing. However, authors must be aware of predatory journals and publishers while submitting their academic works for publication. Publishing in predatory journals is just a waste of efforts, money, and time as it does not add any scientific merits to the authors. The practice of predatory publishing can also damage the reputation of institutions and funding agencies. Therefore, there is an urgent need for awareness among researchers regarding predatory publishing. Local, national and international regulatory bodies should take stern actions against predatory publications while granting research funds and evaluating the researchers' performance for job promotion and academic degrees.
\end{abstract}

Keywords: Academic reputation, predatory journals, research publication

Correct citation: Shrestha, J. (2021). Predatory journals as threats to the academic publishing: a review. Journal of Agriculture and Natural Resources, 4(2), 1-10. DOI: https://doi.org/10.3126/janr.v4i2.33640

\section{INTRODUCTION}

Research publications are necessary for many reasons. For example, academicians need publications for career advancement or for applying in teaching positions; and researchers need this to demonstrate their research and publishing skills, which helps them earn scholarships. Likewise, students need this to get scholarships and improve their professional development and track record. But publishing in a trustworthy journal is hard, requires high-quality research, and may take a long time from submission to publication of articles (Gautam, 2020). Predatory publishing is an unethical practice that erodes the quality of the scientific literature, spreads misinformation and misconceptions now in the public domain (Tiwari, 2020). Predatory journals may steal intellectual property through deception, engage in fraudulent or fake peer review, or list respected researchers on their editorial boards without their knowledge or consents (Musick, 2015). Peer review is minimal or absent in the predatory journals, and the manuscripts are always accepted for publication with an estimated acceptance rate of $80-100 \%$, depending on the journal (Björk, 2019). 
Journal of Agriculture and Natural Resources (2021) 4(2): 1-10

ISSN: 2661-6270 (Print), ISSN: 2661-6289 (Online)

DOI: https://doi.org/10.3126/janr.v4i2.33640

Predatory journals are a global threat. They accept articles for publication, at the author's expense, without performing the promised quality checks for issues like plagiarism or ethical approval. Many researchers have been trapped by predator journals (Grudniewicz et al., 2019). The increase in the number of predatory journals puts scholarly communication at risk. Predatory publishing not only harms or degrades academic reputations but also wastes time, money, resources, and efforts (Shrestha et al., 2020). Predatory publications pose a danger that could undermine the quality, integrity, and reliability of published scientific research works. Such publications also harm the reputation of the universities and research organizations that are connected with these publications. Because a portion of the publishing fees paid to predatory journals comes from public research funds, predatory publishing has been criticized (Vogel, 2017) and is regarded as unethical (Resnik, 2019) for wasting money. Predatory journals often do not readily accept an author's request for withdrawal/retraction of articles (Memon, 2018). If they do, they never refund the publication fees (Klassen, 2019), ask for a "withdrawal fee" of several hundred dollars.

Universities and research organizations should educate researchers, especially juniors, about the existence of predatory journals, the dangers they pose, and ways to avoid them (Shrestha, 2020). In order to guard against publications in predatory journals, authors may use checklists to help detect predatory journals (Cukier et al., 2020). The authors should check "Think Check. Submit." to identify legitimate journals for publication. The universities and research organizations should encourage their students and researchers to publish their research and review works in legitimate journals which are indexed in Web of Science's Journal Citation Reports (JCR), Clarivate Analytics, (formerly part of Thomson-Reuters) or other famous scientific databases such as Scopus, DOAJ, OASPA, PubMed and MEDLINE (Shrestha et al., 2018b). With this background, the objective of this review paper is to create awareness of predatory publications among the research and teaching community, students and readers.

\section{Identifying a predatory journal}

The number of predatory journals and publishers has increased enormously in recent years (Ross-White et al., 2019). Predatory journals ask actively asks researchers for manuscripts. They have no peer review system, no editorial board and are often publish mediocre or even worthless papers. They also ask for huge publication charges (Pacha, 2017). Their goal is to make money, not to produce quality journals. (Beall, 2012). Despite the difficulty in defining them (Cobey et al., 2019), their goal can be characterized, in general, is profit, frequently through the payment of a publication fee or charge that is characteristic of most journals that operate in open-access, albeit not exclusively (Teixeira da Silva \& Tsigaris, 2018). To attain this purpose, the manuscripts are not subjected to serious peer review and, consequently, the quality of what is published is not a purpose of these journals (Ross-White et al., 2019; Watson, 2019; Teixeira da Silva \& Tsigaris, 2018; Cress \& Sarwer, 2019). The criteria to identify Predatory open access publishing are that they are accepting articles quickly with little or no peer review or quality control (Stratford , 2012), aggressively campaigning for academics to submit articles or serve on editorial boards (Butler, 2013), listing academics as members of editorial boards without their permission (Elliott , 2012), appointing fake academics to editorial boards (Neumann, 2012), mimicking the name or web site style of more established journals (Kolata , 2013), making misleading claims about the publishing operation, such as a false 
Journal of Agriculture and Natural Resources (2021) 4(2): 1-10

ISSN: 2661-6270 (Print), ISSN: 2661-6289 (Online)

DOI: https://doi.org/10.3126/janr.v4i2.33640

location (Elliott , 2012) and citing fake and non-existing (or non existing) impact factors (Beall , 2014) .They promise a high Impact Factor and a high number of citations, claiming their journals are influential and field leaders (Anonymous, 2020a).

Some key characteristics of predatory journals (Adapted by UNC, 2020) are

- Exploits faculty, researchers, and scholars for money

- Solicits authors, reviewers, and editors via spam emails

- Provides incomplete, incorrect, or no information about publication fees

- Steals legitimate journals' identities, content, and logos

- Implies value by using misleading or fake metrics, fake impact factors

- Performs little or no copyediting, proofreading, or peer review, or reviewers may be unqualified.

- No editor, fake editors, no review board, insufficient number of board members, or same editors for journals of different disciplines

- Publishes a large set of unrelated journals, same editor board for different journals

Predatory journals often try to mislead researchers by providing names of metrics that are very similar to real metrics, they are CiteFactor, Digital Online Identifier-Database System, Global Impact Factor, Institute for Science Information, Journals Impact Factor (JIFACTOR), Science Impact Factor, Scientific Journal Impact Factor and SCIJOURNAL.ORG (International Scientific Institute) (Adapted by UNC, 2020).

There is an international initiative called "Think. Check. Submit." (http://thinkchecksubmit.org) that helps the researchers to identify trusted journals for publication. It contains a simple checklist researcher can use to assess the credentials of a journal or publisher. Before you submit your work to a journal, use this checklists (from Think.Check.Submit.Initiative) to find out if it is a genuine one (Adapted by Pacha, 2017).

- Do you or your colleagues know the journal?

- Can you easily identify and contact the publisher?

- Is the journal clear about the type of peer review it uses?

- Are articles indexed in services that you use?

- Is it clear what fees will be charged?

- Do you recognize the editorial board?

- Is the publisher a member of a recognized industry initiative (COPE, DOAJ, OASPA)?

\section{Victims of predatory publishing}

Predatory publishers often prey on innocent researchers who are unaware of the threats of predatory publishing. Predators exploit careless, apathetic or lazy practices. Predatory journals cleverly camouflage themselves by closely approximating the forms of existing credible journals via having similar titles as very well-established or -credible journals (Clark \& Thompson, 2017). Predatory journals have helped many pseudo-researchers to prosper (Pacha, 2017). In a relatively short period, they want to publish several papers that will boost their intellectual reputation or the influence of their curriculum vitae (Shrestha, 2020). New scholars from developing countries are said to be especially at risk of being misled by predatory 
Journal of Agriculture and Natural Resources (2021) 4(2): 1-10

ISSN: 2661-6270 (Print), ISSN: 2661-6289 (Online)

DOI: https://doi.org/10.3126/janr.v4i2.33640

publishers (Kearney, 2005; Xia et al 2014). The spectrum of victims of predatory journals varies widely and includes inexperienced, early-career and naive researchers from both developing and high- to upper middle-income countries, together with experienced researchers (Balehegn, 2017; Erolsson \& Helgesson, 2018; Memom, 2017). Young academics (MS, Ph.D. students) from universities and young researchers from scientific organizations, regardless of the persuasive criteria of their degree, career advancement, etc., are attempting to publish in predatory journals. Attaining a publication in a predatory journal is not neutral on a CV or résumé but an active demerit that harms the external reputations of all those involved. This may be less damaging to senior academics with many publications to counter this impression - but is very damaging to those seeking to establish their credibilities, such as masters and doctoral students and early career researchers (Clark \& Thompson, 2017). Young scientists and young scholars are easy victims of predatory publications (Shrestha et al., 2020). Predatory publication is a global problem.

\section{Harms caused by predatory journals}

Since the advent of predatory publishing, there have been tens of thousands of researchers who have earned Masters and Ph.D. degrees, been awarded other credentials and certifications, received tenure and promotion, and gotten employment - that they otherwise would not have been able to achieve - all because of the easy article acceptance that the pay-to-publish journals offer (Beall, 2017). Publishing in a predatory journal as a senior $\mathrm{PhD}$ student suggests a lack of planning and scientific publishing rigor that is absolutely required of a scientist. Publishing in a predatory journal or voluntarily serving on the editorial board of one can hurt researchers' careers. When such articles or editorial board services are recorded on one's curriculum vitae, it can actually hurt a researcher's chances of earning promotion and tenure. External reviewers may take note of one's publication in easy-acceptance journals, penning evaluations that hurt a career rather than help it (Glick, 2016).

The predatory journals are a threat to the field of management research because they can be used strategically to legitimize management ideologies, morally questionable business models, or discriminatory HR practices. These journals can be used to de-legitimize the management discipline (or sub-disciplines) through bogus articles (Dobusch \& Heimstädt, 2019). Without an adequate peer review process and limited editorial oversight in predatory journals, there are no mechanisms to verify if the quality of the medical articles is correct and avoid findings that can be potentially harmful to patients and others. Predatory journals are eroding the credibility of the scientific literature in the health sciences as they actually boost the propagation of errors (Forero et al., 2018). By publishing in predatory journals, scientists have quickly made their works useless, illegal, and stigmatized (Shrestha et al., 2020). Predatory publications pose a danger that could undermine the quality, integrity, and reliability of published scientific research works. Predatory publications also harm the reputation of the universities and research organizations which are connected with these publications.

The quality of the paper submitted is not assessed by predatory publishers; little or no editing is applied to it and there might be a low standard or no peer review process. Poor grammar and spelling appear in published articles. Their website might not be stable and articles might disappear after a certain period. A paper might be kept online only for a short period and the publisher might even decide to stop operating with no notice (Anonymous, 2020a). 
Journal of Agriculture and Natural Resources (2021) 4(2): 1-10

ISSN: 2661-6270 (Print), ISSN: 2661-6289 (Online)

DOI: https://doi.org/10.3126/janr.v4i2.33640

\section{Choosing right publisher to publish}

The priority for publication should be given in those journals which are owned by Universities, Government Research Organizations, Associations of university presses and well established companies (IEEE, ACM, Elsevier, Springer, Routledge, Wiley, Sage, Emerald, Taylor and Francis, Sciendo and De Gruyter etc.) (Shrestha et al., 2018 a), professional Societies like Nepal Geological Society etc. The journals associated with universities or learned societies such as MIT Press, Oxford University Press, and Cambridge University Press, or the American Physical Society, Royal Society of Chemistry, etc., are prominent publishers. Publication should be avoided in those journals which are owned by unregistered societies/associations or private publishers. The publishers who have registered in DOAJ, Committee on Publication Ethics (COPE) is considered good to publish. Selection of nonprofit academic publishers and open access publishers is equally important. The journals managed by INASP and African Journals Online (AJOL) are trusted journals. The authors can judge the quality of journals through their JPPS criteria (The Journal Publishing Practices and Standards)(https://www.journalquality.info/en/).

\section{Identifying legitimate or predatory publisher}

- Suspect unsolicited email invitation from the publisher to publish your paper and your work as reviewer or editor in the editorial office. Legitimate scientific journals may encourage authors to write articles or serve on boards, but publishers know you and your work in detail and you are a recognized expert.

- Think. Check. Submit. This website will get you started on thinking about where you are submitting your work. For any journal that you do not already know, use multiple checks for legitimacy, not just one or two.

- The Committee on Publishing Ethics has published the third version of their Principles of Transparency and Best Practice in Scholarly Publishing.

- Consult the Directory of Open Access Journals (DOAJ) to identify open access journals that have passed several tests of legitimacy and quality. Be aware, there may be journals listed in the DOAJ that are or have turned predatory. Use multiple criteria to assess a journal's legitimacy.

- Look at the journal web site. Is it pretending to be part of a well-known group of journals but isn't? Is the journal published regularly? Does the contact information for the publisher look legitimate? Are there clear publishing, archiving, and peer review policies stated? Read some of the articles yourself to assess their quality.

- Is the journal indexed in a literature database that sets standards for inclusion like PubMed, Web of Science, Scopus, PsycInfo, CINAHL, ERIC, and other subjectspecific databases? Google Scholar does not set such standards for inclusion. (Make sure that the journal is actually indexed currently by the database and not that just a few articles from that journal appear in the database. Your subject librarian can help you with this. Some legitimate journals from the past have had their names stolen) 
Journal of Agriculture and Natural Resources (2021) 4(2): 1-10

ISSN: 2661-6270 (Print), ISSN: 2661-6289 (Online)

DOI: https://doi.org/10.3126/janr.v4i2.33640

- Look at the names of the editor and editorial board. Are they recognized people in your field? Contact some of them if you have concerns because this can also be a scam.

- If in doubt, find another journal. There are many open access journals at all levels, from top tier high impact factor journals to more specialized niche journals which are peer reviewed and respected.

\section{Harmful effect of citations from predatory journals}

The papers you publish in predatory journals are unlikely to be cited, which will affect the impact of your research and, if you care about such things, it will stop metrics such as your hindex from growing as fast as it could (Anonymous, 2020b). The articles from predatory journals have rarely been cited in legitimate publications. A study indicated that $60 \%$ of the articles in predatory journals attracted no citations over a 5-year period (Brainard, 2020). Authors should not publish in, or cite articles published in, predatory journals, even if an individual study appears credible. If researchers cite articles in scientifically questionable journals, their reputation could risk as much damage as if they appear as authors in such publications (Severin \& Low, 2019). Citation of articles from predatory journals should be discouraged. The students, academics, and researchers should be careful to avoid predatory publications and their citations (Shrestha et al., 2020). Scopus and other widely used citation databases do not list most predatory journals, so the team used Google Scholar to count citations. One of ICMJE's recommendations to authors is to "avoid citing articles in predatory or pseudo-journals." Similar ideas appear in the COPE to "discourage citation of articles published in fake journals."

\section{Ways to discourage predatory publishing}

Research institutions should encourage their researchers to publish their articles in reputed journals indexed in Web of Science's Journal Citation Reports (JCR), Clarivate Analytics, formerly part of Thomson-Reuters) or other famous scientific databases such as Scopus, DOAJ, COPE, OASPA, PubMed and MEDLINE (Shrestha et al., 2018b; Severin and Low, 2019).

Universities and research organizations should educate researchers, especially research scholars about the existence of predatory journals, the dangers they pose, and ways to avoid them (Shrestha, 2020). The problem of potential open access predatory publications must be actively discussed at national, regional, and world levels within academic communities (Shrestha et al., 2018b). Predatory publications must be avoided or excluded while evaluating $\mathrm{CVs}$ of researchers for job promotion and releasing the research grants.

The following actions should be taken to stop predatory publications (As adopted by Rogovchenko, 2017)

- "Educational campaign" should be widely arranged to discourage publication in predatory journals, especially with master and doctoral students and researchers in the beginning of their career (they may often be under the pressure and badly need to publish fast - thus, easy catch by predator journals).

- Publications in such journals should not be counted towards employment or promotion. On the contrary, they should be considered by employers as negative factors. 
Journal of Agriculture and Natural Resources (2021) 4(2): 1-10

ISSN: 2661-6270 (Print), ISSN: 2661-6289 (Online)

DOI: https://doi.org/10.3126/janr.v4i2.33640

- Researchers should avoid citing papers published in predatory journals.

- Bibliometric indicators for publications in predatory journals may be organized with negative values thus decreasing the author's scores and impact. One may also think of a negative score for citations to papers in predator journals.

According to Wehrmeijer, (2014), the three possible methods to stop predatory journals are black- and white-lists, open peer review systems and new metrics. Black- and whitelists have set up rules and regulations that credible publishers and journals should follow. Open peer review systems should make it harder for predatory publishers to make false claims about their peer review process. Metrics should measure more aspects of research impact and become less liable to gaming. Many scholars wish to include a large number of publications in their CVs when applying for a new job or for promotion. The members of selection committee should not be fooled by a list of predatory publications (Anonymous, 2020b).

\section{CONCLUSION}

Many students, teachers, researchers my not be aware of the predatory publications. Predatory publications are just a waste of time, resources, money, and efforts. Such publications reduce the authenticity, reliability, and validity of the scientific works published, which undermine the trust and confidence of researchers, academicians, general public. Publishing research works in predatory journals not only does it harm to authors' CVs, brings down their academic credibility into question but also devalues their research works. In order to save long run academic integrity, true and reliable information regarding the predatory journals is utmost among the scientific world to publish but not to perish. The students, academics, and researchers should be careful to avoid predatory publications and their citations

\section{Funding}

No funds were involved in supporting this work.

\section{Author's contribution}

J. Shrestha wrote this article.

\section{Conflict of Interest}

The author declares that there are no conflicts of interest regarding publication of this manuscript.

\section{REFERENCES}

Anonymous. (2020a). How to recognize the predatory publisher. Retrieved from https://www.sciendo.com/news/how-to-recognize-the-predator-publisher

Anonymous. (2020b). Predatory Publishing. Will publishing in predatory journals harm your CV?. Retrieved from https://predatory-publishing.com/will-publishing-inpredatory-journals-harm-your-cv

Balehegn, M. (2017). Increased publication in predatory journals by developing countries' institutions: what it entails? and what can be done? International Information and Library Review, 49(2), 97-100. 
Journal of Agriculture and Natural Resources (2021) 4(2): 1-10

ISSN: 2661-6270 (Print), ISSN: 2661-6289 (Online)

DOI: https://doi.org/10.3126/janr.v4i2.33640

Beall, J. (2012). Predatory publishers are corrupting open access. Nature, 489(7415), 179.

Beall, J. (2017).What I learned from predatory publishers. Biochem Medica, 27, 273-278.

Björk, B. (2019). Acceptance Rates of Scholarly Peer-reviewed Journals: A Literature Survey.

El Profesional De La Información. 28 (4), 1-9. DOI: http://doi.org/10.3145/epi.2019.jul.07.

Brainard, J. (2020). Articles in 'predatory' journals receive few or no citations. Science, 367 (6474), 129. DOI: http://dx.doi.org/10.1126/science.aba8116

Butler, D. (2013).Investigating journals: The dark side of publishing. Nature, 495 (7442), 433 435.

Clark, A., \& Thompson, D. (2017). Five (bad) reasons to publish your research in predatory journals. Journal of Advanced Nursing, 73(11), 2499-2501.

Cobey, K. D., Grudniewicz, A., Lalu, M. M., Rice, D. B., Raffoul, H., \& Moher, D. (2019). Knowledge and motivations of researchers publishing in presumed predatory journals: A survey. BMJ Open, 9(3), e026516. DOI: http://dx.doi.org/10.1136/bmjopen-2018-026516

Cress, P. E., \& Sarwer, D. B. (2019). Predatory journals: An ethical crisis in publishing. Aesthetic Surgery Journal Open Forum, 1(1), 1-3. DOI: https://doi.org/10.1093/asjof/ojz001

Cukier, S., Helal, L., Rice, D.B., Pupkaite, J., Ahmadzai, N., Wilson, M., Skidmore, B., Lalu, M.M., \& Moher, D. (2020). Checklists to detect potential predatory biomedical journals: a systematic review. BMC medicine, 18, 1-20.

Dobusch, L., \& Heimstädt, M. (2019). Predatory publishing in management research: A call for open peer review. Management Learning, 50(5), 607-619.

Elliott, C. (2012). On Predatory Publishers: a Q\&A With Jeffrey Beall". Brainstorm. The Chronicle of Higher Education (June 5, 2012).

Eriksson, S., \& Helgesson, G. (2018). Time to stop talking about 'predatory journals. Learned Publishing, 31(2),181-183.

Forero, D.A., Oermann, M.H., Manca, A., Deriu, F., Mendieta-Zerón, H., Dadkhah, M., Bhad, R., Deshpande, S.N., Wang, W., \& Cifuentes, M.P. (2018). Negative effects of predatory journals on global health research. Annals of global health, 84(4), 584589. DOI: https://doi.org/10.29024/aogh.2389.

Gautam, B. (2020). Where NOT to publish: Predatory Journals. Retrieved from https://linkphysio.com/where-not-to-publish-predatory-journals/

Glick, M. (2016). Publish and perish. The Journal of the American Dental Association, 147(6), 385-387.

Grudniewicz, A., Moher, D., Cobey, K. D., Bryson, G. L., Cukier, S., Allen, K., ... \& Ciro, J. B. (2019). Predatory journals: no definition, no defence. Nature, 576(7786), 210212.

Kearney, M. H. (2015). Predatory Publishing: What Authors Need to Know. Research in Nursing \& Health, 38(1), 1-3. DOI: http://dx.doi.org/10.1002/nur.21640. PMID 25545343.

Klassen, B. (2019). Predatory Journals Can Wreak Havoc a Student's Wallet and Tarnish Their Professional Reputation. The Runner. Available online: https://runnermag.ca/2019/04/predatory-journals-can-wreak-havoc-a-studentswalletand-tarnish-their-professional-reputation/ 2019, April

Kolata, G. (2013).For Scientists, an Exploding World of Pseudo-Academia. The New York Times (April 7, 2013). 
Journal of Agriculture and Natural Resources (2021) 4(2): 1-10

ISSN: 2661-6270 (Print), ISSN: 2661-6289 (Online)

DOI: https://doi.org/10.3126/janr.v4i2.33640

Memon, A.R. (2017). ResearchGate and impact factor: a step further on predatory journals. Journal of Pakistan Medical Association, 67(1), 148-149.

Memon, A.R. (2018). How to Respond to and What to Do for Papers Published in Predatory Journals?. Science Editing, 5(2), 146-149. DOI: http://doi.org/10.6087/kcse.140.

Musick, C. (2015). 8 questions and answers about predatory journals: Protecting your research, reputation, and funding from theft and fraud. Retrieved from https://thinkscience.co.jp/en/articles/predatory-journals

Neumann, R. (2012).Junk Journals" und die Peter-Panne". Labor journal (February 2, 2012).

Pacha, A. (2017). What is a predatory journal?. The Hindu. Retrieved from https://www.thehindu.com/sci-tech/science/what-is-a-predatoryjournal/article21039351.ece

Resnik, D.B. (2019). Stewardship of Research Resources. Account. Res., 26 (3), 246-251. DOI: http://doi.org/10.1080/08989621.2019.1585819

Rogovchenko, Y. V. (2017). What actions can be taken to stopping predatory journals?. Retrieved from https://www.researchgate.net/post/What-actions-can-be-taken-tostopping-predatory-journals

Ross-White, A., Godfrey, C. M., Sears, K. A., \& Wilson, R. (2019). Predatory publications in evidence syntheses. Journal of the Medical Library Association, 107(1), 57-61. DOI: https://doi.org/10.5195/jmla.2019.491

Severin, A., \& Low, N. (2019). Readers beware! Predatory journals are infiltrating citation databases. International Journal of Public Health, 64, 1123-1124

Shrestha, J. (2020). Authors beware! Publishing in predatory journals is harmful. Journal of Agriculture and Natural Resources, $3(2), \quad$ 1-8. DOI: https://doi.org/10.3126/janr.v3i2.32293

Shrestha, J., Subedi, S., \& Timsina, K. (2020). Predatory publishing: A threat to the credibility of science. Nepal Journal of Multidisciplinary Research,3(1), 7-14. https://doi.org/10.3126/njmr.v3i1.30214

Shrestha, J., Subedi, S., Shokati, B., \& Chaudhary, A. (2018b). Predatory Journals: A Threat to Scholarly Publishing. Journal of Education and Research,8(1), 89-101. https://doi.org/10.3126/jer.v8i1.25482

Shrestha, J., Subedi, S., Timsina, K., \& Tripathi, M. (2018a). Risk of publication in worthless journals. Journal of Agriculture and Natural Resources, 1(1), 1-5. https://doi.org/10.3126/janr.v1i1.22217

Stratford, M. (2012). Predatory Online Journals Lure Scholars Who Are Eager to Publish. The Chronicle of Higher Education (March 4, 2012).

Teixeira da Silva, J. A., \& Tsigaris, P. (2018). What value do journal whitelists and blacklists have in academia?. The Journal of Academic Librarianship, 44(6), 781-792. DOI: https://doi.org/10.1016/j.acalib.2018.09.017

Tiwari, S. (2020). Predatory Journals: The Need for Academic Honesty in Public Conversations. Retrieved from https://thewire.in/the-sciences/predatory-journalsthe-need-for-academic-honesty-in-public-conversations

UNC (The University of North Carolina). (2020). Choosing Where to Publish: Predatory publishing. Retrieved from https://guides.lib.unc.edu/publish/predatory

Vogel, L. (2017). Rich Nations Are Feeding Research Predators. Canadian Medical Association Journal, $189 \quad$ (42), E1322-E1323. $\quad$ DOI: http://doi.org/10.1503/cmaj.109-5510.

Watson, R. (2019). Predatory journals and the pollution of academic publishing. Journal of 
Journal of Agriculture and Natural Resources (2021) 4(2): 1-10

ISSN: 2661-6270 (Print), ISSN: 2661-6289 (Online)

DOI: https://doi.org/10.3126/janr.v4i2.33640

Nursing Management, 27(2), 223-224. DOI: https://doi.org/10.1111/jonm.12739

Wehrmeijer, M. (2014). Exposing the predators. Methods to stop predatory journals. Retrieved from https://studenttheses.universiteitleiden.nl/handle/1887/28943

Xia, J., Harmon, J. L., Connolly, K. G., Donnelly, R. M., Anderson, M. R., \& Howard, H. A. (2015). Who publishes in "predatory" journals?. Journal of the Association for Information Science and Technology, 66(7), 1406-1417. 